REPLY TO LETTER

\title{
Post-surgical thyroid ablation in intermediate risk-differentiated thyroid cancer patients
}

Furio Pacini

Section of Endocrinology and Metabolism, Department of Internal Medicine, Endocrinology and Metabolism and Biochemistry, University of Siena, Policlinico Santa Maria alle Scotte, Viale Bracci 1, 53100 Siena, Italy

(Correspondence should be addressed to F Pacini; Email: pacini8@unisi.it)

\section{Reply to the Letter to the Editor by Dr Rosario}

We thank Dr Rosario for his comment. He is right when stating that the rate of ablation was rather low, but this is not surprising because we are dealing with patients that may be metastatic at the moment of ablation and will not be cured with a single ablative dose of radioiodine. In this regard, our rates of ablation are in line with those reported in the literature.

The aim of ablation is to remove the normal thyroid remnant. To eradicate metastases is treatment and not ablation. The aim of our study was not to see how many times an ablative dose was able to cure the patient but just to see whether low or high ablation activities had an impact on the final outcome of patients who continued to be treated with additional therapeutic doses of radioiodine or other therapies whenever they had persistent or recurrent disease.
The last sentence of Rosario's letter '...these patients should be treated with even higher 131-I activities' would imply that he pretends to cure metastatic patients just with one single dose of radioiodine. This is not current practice.

\section{Declaration of interest}

The authors declare that there is no conflict of interest that could be perceived as prejudicing the impartiality of the research reported.

\section{Funding}

This research did not receive any specific grant from any funding agency in the public, commercial or not-for-profit sector.

Received 29 July 2013

Accepted 12 August 2013 